\title{
From the Editor of Sexuality and Disability: 2020 ... A Year of Awareness of What is New and What Has Always Been
}

\section{Sigmund Hough ${ }^{1}$}

Accepted: 27 January 2021 / Published online: 6 February 2021

(c) The Author(s), under exclusive licence to Springer Science+Business Media, LLC part of Springer Nature 2021

The journal, Sexuality and Disability, continues to be a professional home and a place of professional rejuvenation for study. Many have followed the journal over the decades since the 1970's. If you are new to the journal, we always give to you a "BIG WELCOME" and invite you to participate as a reader, author, academician, clinician, educator, service provider, researcher, advocate, or person seeking information. Over the years of contribution to the literature on sexuality and disability healthcare, we have been a part of the growth, understanding, and advocacy. Most important, we continue to be a part of the change in how we look and examine the topic, the needs, and the response in terms of best practice-evidence based approaches. With the intelligence, experience, motivation, and supportive dedication from our authors, readership, international peer reviewers and editorial board members, and resources combined with valuable guidance from the Springer Staff; our journal's mission continues to be meaningful. This international effort continues as a strength in the field of sexuality and disability.

Since 1978, Sexuality and Disability has pushed for pragmatic knowledge to have impact on education, research, and practice. Sexuality and Disability makes available original impact articles addressing the mental health and medical healthcare aspects of sexuality in relation to rehabilitation, hospital, academic, and community settings, publishing upto-date articles, case studies, clinical practice reports, reviews, featured articles, historical articles, special grand rounds topics, brief research reports, and survey data reports. Value benefit is provided to authors through worldwide electronic exposure and professional access, while readership gains knowledge from scholarly contributions which advance the field through research, evidence-based, best-practice and educational articles. Individual contributions from the local and international community delivers a wealth of information with broad perspectives on the topic of sexuality and disability.

The year 2020 was clearly a year of increased awareness of what is new and what has always been on various levels. As we start 2021, we continue the opportunity to learn, share, improve and gain perspective. A quick review tells us that sexuality and disability remain important topics. A longer review will hopefully inform us how best to improve, survive, endure, manage and be better equip to handle the challenges and concerns of tomorrow. Our interest continues with the agenda to promote and support the diversity and

Sigmund Hough

Sigmund_Hough@hms.harvard.edu

100 Cummings Center, Suite 207, Beverly, MA 01915, USA 
inclusion across editorial board members, peer review members, authors, publications and readership.

Thank you for joining our professional efforts.

Sigmund Hough, Ph.D., ABPP/rp

Editor-in-Chief, Sexuality and Disability

Sigmund_Hough@hms.harvard.edu

Publisher's Note Springer Nature remains neutral with regard to jurisdictional claims in published maps and institutional affiliations. 